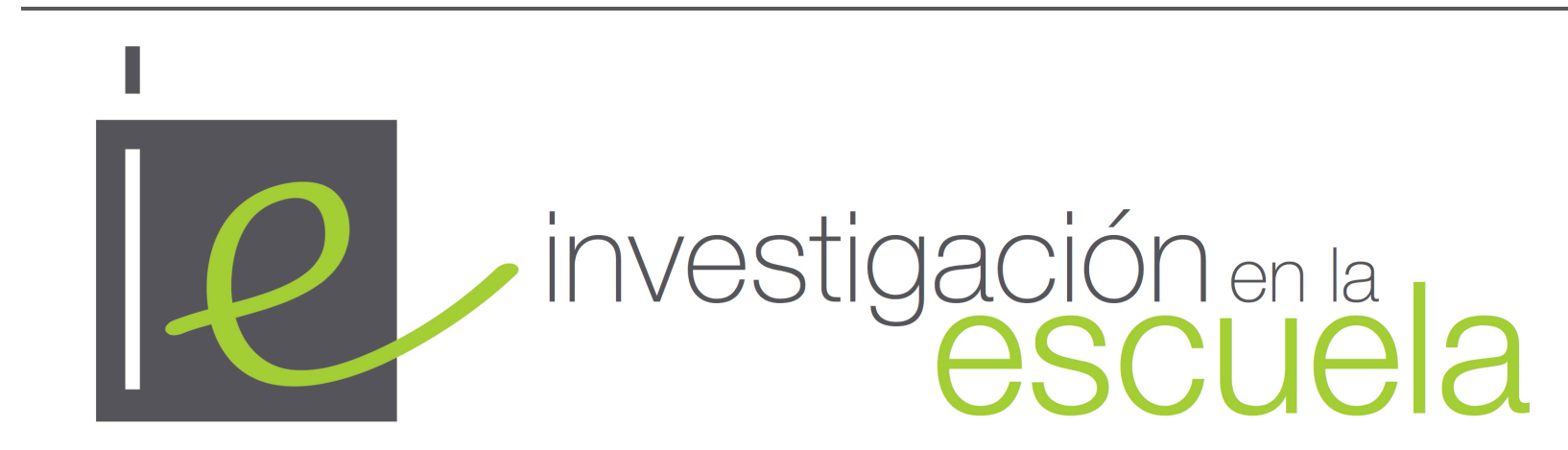

Revista internacional de investigación e innovación educativa

\title{
La "atención a la diversidad" como oportunidad. La perspectiva del proyecto Gea-Clío
}

\author{
Amaldo Mira Pérez. \\ Universitat de València \\ España
}

Citación: Mira Pérez, A. (2019). La "atención a la diversidad” como oportunidad. La perspectiva del proyecto Gea-Clío. Investigación en la Escuela, 98, 31-44.

doi: http://dx.doi.org/10.12795/IE.2019.i98.03

Resumen: En 1989 se conformó en Valencia (España) el grupo de innovación e investigación pedagógica Gea-Clío, centrado en torno a la didáctica de la geografía y la historia desde una perspectiva progresista y crítica. Un año después (en 1990) se inició en España una reforma educativa de gran calado que extendió la obligatoriedad de la escolarización hasta los 16 años. La implementación de dicha reforma conllevó la aparición de serios problemas en el sistema educativo español. Se analiza la génesis de dichos problemas, las soluciones conservadoras aplicadas durante los últimos años y sus efectos. A continuación se exponen los enfoques y las propuestas dadas a esos nuevos retos desde el grupo Gea-Clío, así como los resultados obtenidos.

Palabras clave: "Ciencias sociales"; "innovación pedagógica"; "reforma educativa"; "didáctica"; "enseñanza obligatoria"; "enseñanza secundaria"; "fracaso escolar".

"Attention to diversity" as an opportunity. The perspective of the Gea-Clío project Abstract: In 1989, the group of pedagogical innovation and research Gea-Clío was set up in Valencia (Spain). It focused on didactics of geography and history from a progressive and critical 
perspective. A year later (in 1990) a major educational reform was initiated in Spain, which extended the compulsory schooling up to 16 years. The implementation of this reform led to the appearance of serious problems in the Spanish educational system. The genesis of these problems, the conservative solutions applied during the last years and their effects are analyzed. The approaches and proposals given to these new challenges by the Gea-Clío group, as well as the results obtained, are explained here.

Key words: Social sciences"; "educational innovation"; "educational reform”; "didactics"; "compulsory education"; "secondary education"; "school failure".

\section{"L'attention portée à la diversité" comme une opportunité. La perspective du projet Gea- Clío}

Resumè: En 1989, le groupe d'innovation pédagogique et de recherche Gea-Clío a été créé à Valence (Espagne), autour de la didactique de la géographie et de l'histoire dans une perspective progressive et critique. Un an plus tard (en 1990), une importante réforme de l'éducation a été lancée en Espagne, qui a porté le caractère obligatoire de la scolarité jusqu'à 16 ans. La mise en œuvre de cette réforme a entraîné l'apparition de graves problèmes dans le système éducatif espagnol. La genèse de ces problèmes, les solutions conservatrices appliquées au cours des dernières années et leurs effets sont analysés. On trouvera ci-dessous les approches et les propositions du groupe GeaClío face à ces nouveaux défis, ainsi que les résultats obtenus.

Mots-clés: "Sciences sociales"; "innovation pédagogique"; "réforme de l'enseignement"; "didactique"; "enseignement obligatoire"; "enseignement secondaire"; "échec scolaire".

\section{Introducción}

En el año 1989 nacía en España, más concretamente en el País Valenciano, el grupo de investigación y renovación pedagógica Gea-Clío. Rápidamente Gea-Clío se consolidó como un punto de encuentro de profesionales de la enseñanza de la geografía y la historia estrechamente vinculados con la docencia y totalmente comprometidos con la renovación en clave progresista de su profesión y su campo de conocimiento. ${ }^{1}$ A lo largo de los años el grupo ha trabajado y participado como tal en multitud de proyectos de todo tipo, pero siempre ha conservado sus señas de identidad originarias: vinculación con la práctica docente y renovación pedagógica. Una renovación pedagógica y metodológica que arranca desde sus mismos orígenes y que, entre otras cosas, plantea una respuesta pedagógica alternativa frente a visiones fragmentadoras-segregadoras de la realidad escolar que hoy pugnan por hegemonizar el espacio educativo en todos los niveles. Una pieza clave en ese discurso fragmentador-segregador es el constructo teórico de "diversidad", conceptualizada ésta como problema. Por el contrario, Gea-Clío entiende la diversidad no como una anomalía sino como una riqueza susceptible de ser aprovechada en el proceso educativo de construcción de la ciudadanía. Pero antes de avanzar en las propuestas pedagógicas de Gea-Clío es necesario que nos detengamos en la génesis de este término aparentemente técnico, atemporal y neutro: el concepto de "diversidad".

\section{El origen de la "diversidad" en el sistema educativo español: genealogía de un "problema"}

\footnotetext{
${ }^{1}$ Sobre el surgimiento y consolidación del grupo así como sobre su dinámica de trabajo interna, vid. Souto, 2011a.
} 
La segunda mitad de los años 80 del pasado siglo fue una época de cambio profundo en España en todos los ámbitos y también por supuesto en el terreno de la educación. Una vez asentada la transición política que llevó al país desde una dictadura de raíz fascista hasta una democracia integrada en Europa, tocaba definir cómo iban a ser los pilares de esa nueva democracia: El sistema sanitario, ¿sería público o se optaría por un modelo similar al estadounidense? El ejército, ¿continuaría basándose en el servicio militar obligatorio o por el contrario se profesionalizaría por completo? Y en la enseñanza, ¿cuál iba a ser el camino a seguir?

Fue en este contexto de debate y efervescencia política y social en el que en el año 1990 legislativamente se acabaron de trazar las líneas maestras del que sería el nuevo sistema educativo español: ese año se promulgó la Ley de Ordenación General del Sistema Educativo, más conocida por sus iniciales, LOGSE. Conjuntamente con la $\mathrm{LODE}^{2}$, ambas leyes configuraban la enseñanza en España como un sistema "público" y "obligatorio" hasta los 16 años. La enseñanza privadaconcertada sólo se contemplaba como una eventualidad temporal que sería sufragada económicamente por el Estado sólo hasta que éste lograse extender y fortalecer suficientemente la red pública. En el futuro inmediato, una vez consolidada la red pública de educación desde la enseñanza primaria hasta la universidad, desaparecerían estos acuerdos. Treinta años después la realidad es otra bien distinta: la red de centros concertados, en manos mayoritariamente de la Iglesia católica, continúa acaparando el dinero del Estado y escolarizando bajo sus reglas a una parte considerable de los niños y niñas españoles. En el conjunto del Estado en el año 2017 la enseñanza concertada abarcaba el 26\% del sistema (MEFP 2018, p. 4). En la práctica, su proporción en zonas urbanas es mucho mayor, siendo por el contrario prácticamente testimonial en zonas rurales, de menor interés "estratégico" para los propietarios de la red concertada (mayoritariamente organismos y fundaciones vinculadas la Iglesia católica española). En la Comunidad de Madrid, una región fuertemente urbanizada, los centros de titularidad privada son un $46 \%$ del total. En el País Vasco, una región de similares características, la cifra asciende al 50\% (MEFP, 2018, p. 6). Estos centros privados-concertados además practican de forma subrepticia una selección del alumnado en función de su calidad académica: los niños y niñas considerados "problemáticos" son rechazados de facto y desviados a la red educativa pública.

Pero volvamos a 1990. Hasta ese momento, en España la escolarización era obligatoria sólo hasta los 14 años. Sin embargo con la nueva legislación esta obligatoriedad se alargó hasta los 16. Además, la prolongación en dos años de la escolaridad obligatoria vino acompañada por la creación de una nueva etapa educativa, la Educación Secundaria Obligatoria, que abarcaba el tramo 12-16. El nuevo diseño del sistema educativo comenzó a implementarse lentamente, quedando totalmente implantado en todas las autonomías (regiones/estados) de España en torno al año 2000, 10 años después de la promulgación de la ley.

En perspectiva, uno de los principales problemas con los que se encontró la implementación y consolidación del nuevo sistema fue el hecho de que el personal docente destinado a gestionar la nueva Educación Secundaria Obligatoria, es decir, el tramo 12-16, eran mayoritariamente los docentes que hasta ese momento habían trabajado en la enseñanza post-obligatoria no universitaria (enseñanzas pre-universitarias, enseñanzas profesionales, etc.) Por ello, la experiencia profesional de este profesorado se encontraba lejos de los problemas y del día a día de lo que es la docencia en una etapa educativa obligatoria (Moreno y García, 2008, pp. 81-82). Además, durante la implementación del nuevo sistema paralelamente se fue acabando con las bolsas de absentismo escolar crónico que aún quedaban dispersas por diversas áreas del país. Así, el resultado fue doble: por un lado, toda la población en edad escolar ahora estaba "efectivamente" escolarizada, desde los 6 hasta los 16 años. Y por otro, la mayoría del personal profesional encargado de gestionar el último tramo de esta

${ }^{2}$ Ley Orgánica reguladora del Derecho a la Educación, promulgada en 1985. 
escolarización obligatoria (12-16) no estaba familiarizado ni con la naturaleza de la etapa (obligatoria) ni tampoco había sido previamente entrenado para afrontar los problemas inherentes a la misma. El profesorado en cuestión tenía una formación universitaria en sus respectivas disciplinas extremadamente sólida, pero su formación pedagógica era sin embargo bastante magra. A lo sumo, estos profesionales habían recibido una preparación pedagógica fragmentaria y "voluntaria", esto es, aquellos docentes que no habían querido recibir formación no habían sido obligados a cursarla. De hecho, el 40\% de ellos manifestaba de forma explícita que consideraba inútil este tipo de formación (Moreno y García, 2008, p. 133).

Casi de inmediato, al escolarizar "realmente" a toda la población entre 6 y 16 años, comenzaron a aparecer problemas tanto de rendimiento escolar como incluso de disciplina, sobre todo en la secundaria. En el año escolar 2003-2004 un tercio del alumnado salía de la educación secundaria obligatoria (ESO) sin obtener el título de graduado: un 30\% de fracaso escolar puro y duro (MEC, 2006). ¿Qué estaba sucediendo? Lo que estaba pasando era sencillamente que, especialmente en las aulas de la nueva etapa 12-16, el alumnado menos "adecuado" que apenas hacía unos años era descartado por el sistema escolar como muy tarde a los 13 años, ahora era "obligado" a permanecer en las aulas, y además hasta los 16 años. Esto era obviamente un cambio radical. Pero la renovación pedagógica que debería haber acompañado a esta "revolución escolar" sencillamente no había tenido lugar. Las administraciones educativas, que deberían haber abanderado, diseñado e implementado esta renovación pedagógica mediante un plan sistemático de formación de su personal docente, sencillamente se limitaron a tutelar iniciativas fragmentarias en las que el personal docente participaba de forma totalmente voluntaria. Legislativamente sí se llevaron a cabo todo tipo de cambios, rediseñando el sistema hasta sus más mínimos detalles y modificándose en profundidad los currículos de las distintas áreas de la nueva educación secundaria: todo sobre el papel. Pero en la práctica apenas se rozaron las metodologías con las que esos currículos iban a ser impartidos en las aulas (Moreno y García, 2008, pp. 36-37). Así, a pie de aula la reforma educativa se materializó en la aplicación de nuevos currículos pero por profesionales que en su mayoría continuaban rigiendo su práctica cotidiana por principios pedagógicos y metodologías propias de las enseñanzas no obligatorias (en las que eran expertos). Pero, ¿cuáles son los rasgos metodológicos comunes a las enseñanzas regladas no obligatorias?

En una enseñanza oficial no obligatoria sistemáticamente se establecen unos niveles de logro a partir de los cuales la institución certifica que el estudiante ha alcanzado los estándares mínimos de la titulación en cuestión. El estudiante que no logra superar esos mínimos sencillamente es descartado. La metodología pedagógica en estos entornos educativos se caracteriza así por su carácter "selectivo". El docente es enseñante pero a la vez es el juez encargado de medir y en su caso otorgar la calificación/titulación correspondiente, cuidadosamente plasmada en forma numérica. Obviamente, el estudiante que inicia un itinerario educativo no obligatorio lo hace de forma voluntaria, y por lo tanto tiene un interés alto en lograr la titulación correspondiente y en hacerlo con la mejor nota posible. Además, afronta con naturalidad la filosofía inherente al sistema y acepta de buen grado la plasmación numérica de su éxito (o su fracaso) por parte de un docente que a la vez es juez supremo, si no temido, sí absolutamente respetado, más allá de su calidad como enseñante. Obviamente, en el marco de una enseñanza de este tipo una pieza clave para el funcionamiento del sistema es la "voluntariedad explícita" del estudiante: está ahí y se somete a las reglas del sistema porque quiere.

Pero si a una población escolar obligada por ley a estar cursando una etapa educativa la sometemos a este sistema, estamos incurriendo en una contradicción evidente. Por lo tanto, no van a tardar en surgir todo tipo de disfunciones y problemas. Pues bien, esta situación contradictoria fue la que se dio en los centros de la recién estrenada Educación Secundaria Obligatoria en España en los años 90 del pasado siglo. Así, como resultado de todo ello comenzó a aparecer de forma casi 
inmediata en las aulas una proporción variable de chicos y chicas que no alcanzaban el "nivel" que el viejo sistema, pese a los nuevos currículos, continuaba estableciendo. Chicos y chicas que, una vez "medidos" y señalados como descartables una y otra vez, obviamente no desaparecían del sistema (porque la ley no se lo permitía) sino que permanecían en las aulas, día tras día, acusados de "no trabajar", no mostrar interés, no tener "cultura del esfuerzo", etc. Los más dóciles aguantaban estoicamente. Los más indómitos se convertían en los "maleducados", los "indisciplinados", etc. Había nacido el "problema" de la diversidad.

\section{Las respuestas institucionales a la "diversidad"}

Como hemos señalado, uno de los efectos perversos de la extensión de la educación obligatoria sin un proceso previo de formación docente y renovación metodológica fue el aumento exponencial de la conflictividad en las aulas. Frente a ello la primera respuesta institucional fue aumentar la rapidez en la aplicación y la contundencia de las medidas punitivas destinadas a castigar al alumnado indisciplinado. La escalada en algunos territorios llegó al extremo de nombrar oficialmente al profesorado "autoridad pública” (Generalitat Valenciana, 2010). En el ordenamiento jurídico español esto equivale a investir a un docente del mismo reconocimiento legal que un policía. Pese a ello, no ha mejorado el clima de convivencia en las aulas. El modelo regulativo-punitivo hace ya años que da muestras de un agotamiento y una ineficacia evidentes (Pineda Alfonso y García Pérez, 2014). Las medidas punitivas no han solucionado tampoco los problemas académicos del conjunto del sistema educativo obligatorio. En España, la tasa de idoneidad en alumnas y alumnos de 15 años se situaba en 2016 en el 67\%. Esto quiere decir que un tercio del alumnado de esa edad había repetido curso al menos una vez a lo largo de su vida escolar (INEE, 2018, p. 71). Un problema aparentemente de rendimiento escolar que en realidad es más bien el producto de un sistema exigente en exceso: "España está en niveles próximos a la media en puntuaciones PISA, pero está en niveles récord en repetición de curso [...] si muchos de los jóvenes españoles estudiasen con las condiciones de sistemas educativos como el alemán, el danés, el francés o el británico, no repetirían curso" (Martínez, 2017, p. 143). Cabría pues más bien hablar de problema del sistema antes que de problema académico.

La segunda respuesta institucional se dio prácticamente en paralelo a la anterior y consistió básicamente en el diseño de itinerarios educativos alternativos para los chicos y chicas "inadaptados". Dado que en el itinerario común, la Educación Secundaria Obligatoria, se generaba (y se genera) prácticamente un 30\% de fracaso escolar, para paliar este fracaso y atender educativamente a este alumnado hasta los 16 años, se idearon (y se han continuado ideando a lo largo del tiempo) toda una serie de programas educativos de diversas características cuyo denominador común ha sido el tratar de ofrecer una alternativa educativa al alumnado descartado por el itinerario (y el profesorado) mainstream. Así, desde un principio el sistema educativo obligatorio español, tal cual está configurado en su etapa secundaria, reconoció (y reconoce) implícitamente su incapacidad para atender al conjunto del alumnado. Con el paso del tiempo estos programas se han consolidado como itinerarios alternativos de facto que corren paralelos al itinerario común que supuestamente habría de albergar a "todos" los alumnos y alumnas. No es este el lugar para extendernos pormenorizadamente sobre las características de cada uno de estos programas. Pero sí cabe señalar que su diseño e implementación han sido fragmentarios y discontinuos en el tiempo. Muchos programas aparecen para mutar, cambiar de nombre o desaparecer al cabo de unos pocos cursos escolares. Igualmente, su éxito o fracaso ha dependido casi siempre de la voluntad y la implicación de los profesionales que han estado a pie de aula poniendo en práctica estos programas (Giménez Urraco, 2014). 
Y en estos programas alternativos, ¿cuál ha sido la propuesta metodológica? En general, esta propuesta como tal ha sido inexistente, si por propuesta metodológica entendemos una didáctica alternativa. Lo que en general se ha hecho ha sido agrupar áreas comunes en ámbitos de conocimiento y acto seguido "descafeinar" todo lo posible dichos ámbitos. Un arma pedagógica tan potente y completa como el trabajo por ámbitos (Ruiz y Martínez, 2017) ha quedado así estigmatizada. El planteamiento de fondo es que, dado que estos chicos y chicas han sido descartados por el sistema, se da por sentado y probado que sencillamente son menos inteligentes y capaces que el resto. Por lo tanto, la única manera de atenderles adecuadamente es rebajando la variedad y complejidad de los contenidos curriculares. El resultado es previsible: a pesar de la atención educativa específica recibida, como ya se señalaba hace casi una década, "los alumnos objeto de medidas de diversificación siguen teniendo grandes probabilidades de fracasar" (Fernández Enguita, Mena y Riviere, p. 185). Así, cuando estos chicos y chicas han acabado de cursar estos programas alternativos, siguen presentando un desfase curricular muy significativo con respecto a chicos y chicas de su misma edad. Por consiguiente, se les hace prácticamente imposible continuar estudios, ya que no han adquirido una base académica adecuada. El resultado final: abandono escolar prematuro. En efecto, a pesar de todos los esfuerzos, la disfuncionalidad encubierta pero persistente del sistema mainstream hace que, a pesar de estos programas, una nutrida parte del alumnado español abandone el sistema educativo en cuanto la ley se lo permite. Así, España tiene la segunda tasa de abandono escolar mayor de la Unión Europea (un 18\% en 2017), muy por encima de la media europea (10\%) y tan sólo por detrás de Malta (MEFP, 2018, p. 25). En definitiva, al cumplir los 16 años casi un $20 \%$ de la población escolar española sencillamente no quiere ni oír hablar de aulas y profesores.

\section{La respuesta de Gea-Clío a la diversidad}

Pero una cosa son las respuestas institucionales y otra bien distinta las propuestas renovadoras que desde abajo los colectivos de profesoras y profesores han estado haciendo en España desde (como mínimo) los años 70 del pasado siglo. Es imposible hacer aquí un resumen de lo que ha sido un fenómeno vasto, complejo y multifacético así como prolongado en el tiempo ${ }^{3}$. Pero para entender el espíritu común que animaba a todos estos grupos y movimientos, baste como botón de muestra lo que en el ámbito valenciano ya planteaban en el 1977 un grupo de docentes de Geografía e Historia para los que lo importante era "eliminar la historia maniquea y positivista y evitar la pasividad del alumno, dándole el papel de elemento agente en su propio proceso de aprendizaje" (Grup Germania-75, 1980, p. 5). Y formando parte de esa corriente pedagógica y metodológica alternativa (en el ámbito valenciano) desde finales de los años 80 del pasado siglo ha estado el grupo de renovación e investigación pedagógica Gea-Clío.

Desde el punto de vista del grupo Gea-Clío, la diversidad de alumnos y alumnas que implica una etapa educativa obligatoria no es una anomalía, sino que sencillamente se corresponde con la normalidad. Por lo tanto, partiendo de este principio, es cuando menos incongruente afrontar o contemplar la diversidad como un problema. La diversidad no es más que un rasgo inherente a cualquier colectivo humano. Categorizar implícitamente a una parte de ese colectivo como "inadaptados" no es un mero tecnicismo: es una manera de estigmatizar a esas personas. La carga ideológica del término "diversidad” así empleado es evidente (Tarabini, 2018, p. 48).

En el contexto de una educación obligatoria, entender los problemas de convivencia única y exclusivamente como manifestación de la inadaptación, violencia o asociabilidad del alumno-a es

\footnotetext{
${ }^{3}$ Una buena visión perspectiva de esta cuestión en Duarte, 2018.
} 
igualmente una opción ideológica. En este ejercicio conservador de conceptualización del fenómeno de la indisciplina escolar, la institución escolar escapa incólume, libre de cualquier responsabilidad. El único culpable del conflicto es el individuo. Pero desde Gea-Clío se profundiza en la cuestión paradójicamente dando un paso atrás, tratando de captar el conjunto del paisaje y preguntándose: ¿por qué surge el conflicto dentro del aula?

Una observación detenida del proceso revela que el conflicto no se genera de forma inmediata. El alumno/a indisciplinado no manifiesta estas conductas el primer día de clase, como cabría esperar si estuviésemos frente a un individuo violento o asocial. Los problemas de disciplina aparecen después de semanas durante las cuales este alumno/a ha sido enfrentado a una dinámica de aprendizaje que no puede seguir: clases magistrales y unidireccionales, actividades monótonas y repetitivas sobre esas clases magistrales que a su vez siguen casi al pie de la letra un libro de texto, pruebas basadas exclusivamente en la memorización de los contenidos de ese libro de texto, etc. Cuando el alumno/a manifiesta su dificultad o su creciente desapego al método, sencillamente no hay respuesta. En el marco de esta estructura rígida de enseñanza-aprendizaje sólo hay una opción válida: adaptarse y sobrevivir. Es cuando el alumno/a se encuentra totalmente perdido y abandonado cuando empiezan a darse los problemas, los conflictos y la "indisciplina".

Gea-Clío impugna totalmente este sistema. Esta dinámica de aula no es válida en una enseñanza obligatoria y siempre generará problemas de convivencia. A no ser, claro está, que previamente se excluya del aula a los "inadaptados" (desplazándolos académicamente a programas paralelos e incluso físicamente a espacios segregados). La propuesta que Gea-Clío plantea es la de un aula presidida por la interacción permanente entre todos los participantes. El aula ha de ser horizontal, entendida esta horizontalidad como participación permanente de todos. El discurso no puede ser apropiado en exclusiva por el docente. Así, en esta interacción discursiva, en este proceso dialéctico compartido, el grupo "genera" conocimiento y reflexiones en torno a un contenido problematizado. $\mathrm{Y}$ es en esta interacción permanente en la que de forma natural todo el grupo avanza en el aprendizaje.

Contemplada desde esta perspectiva, la conflictividad se explica de manera bien distinta. Las causas de la conflictividad no se hallan en una supuesta incapacidad congénita del alumno/a en cuestión para comportarse civilizadamente. Muy al contrario, el conflicto no es más que la manifestación de la impotencia para enseñar de una determinada metodología. Si se elimina esa metodología conservadora, la conflictividad y la indisciplina desaparecen.

Pero más concretamente, ¿qué metodología propone Gea-Clío? Epistemológicamente, se parte del siguiente principio: la realidad histórica o geográfica es susceptible de ser explicada, y no sólo descrita. Así, "educar no es suministrar información, sino que sobre todo es reflexionar sobre los datos y problemas de la vida cotidiana." (Pérez, Ramírez y Souto, 1997, p. 2). Y en esa búsqueda de la explicación del fenómeno geográfico o histórico, proporcionados los elementos de juicio y la información necesaria, cualquier individuo pensante puede participar de forma activa. Es decir, la capacidad de interpretación y explicación no es exclusiva del docente, ni este pretende que así sea. Es todo el grupo el que participa de esa capacidad y es por lo tanto todo el grupo el que protagoniza esa tarea de indagación y explicación de la realidad problematizada: "Si estructuramos los contenidos del área en torno a unidades didácticas centradas en la resolución de problemas podremos dotar a nuestros alumnos de los instrumentos cognitivos que les den claves de interpretación para entender mejor el mundo, el medio, en el que viven" (Pérez et al., 1997, p. 3). Con este horizonte presente, obviamente es el docente el que prepara el terreno para que todo ello discurra con fluidez; pero no monopoliza el discurso del aula. Antes bien, promueve activamente que este discurso sea compartido.

Insistimos en que en estas coordenadas metodológicas se está moviendo desde hace décadas toda una corriente pedagógica alternativa en la que se encuadran diversos proyectos y colectivos en 
los que se trabaja a partir de "contenidos escolares no sólo pertinentes desde el punto de vista curricular, sino significativos para los alumnos, fundamentados desde las disciplinas científicas y [con] vinculación real con los problemas sociales" (Pineda Alfonso y García Pérez, 2016, p. 1083). Obviamente, todo ello conduce inevitablemente a repensar el proceso de enseñanza-aprendizaje en su conjunto ya que "problematizar el conocimiento significa interrogar, no suministrar el conocimiento acabado” (Pineda y García Pérez, 2016, p. 1084): en definitiva, las antípodas de la "educación bancaria". A Así, en este proceso de incorporación de la realidad problematizada al aula, cuestiones que la educación bancaria considera totalmente ajenas al currículum, en este marco metodológico son incorporadas al mismo y además con rango de núcleo temático central: el conflicto y la convivencia (o la diversidad), cuestiones relegadas a los márgenes de los currículums oficiales, adquieren de este modo un papel clave (Pineda y García Pérez, 2017).

Pongamos un breve ejemplo actual de la metodología propuesta (desde los 90) por Gea-Clío y que ilustra lo que queremos decir. En este caso, lo que se pretende abordar en el aula es la cuestión de la diversidad dentro de la sociedad española. Lo que sigue es una breve propuesta de cómo iniciar el abordaje de la cuestión a partir de la problematización de la realidad más próxima al alumno/a como paso previo a su reconceptualización. El núcleo temático oficial es "movimientos migratorios". Estamos en un aula de chicos y chicas de 13 años. El titular escrito en la pizarra con el que arranca la sesión es: “¿Nos roban el trabajo?”.

${ }^{4}$ En el sentido "freireiano" del término (Freire, 1970/2005, p. 72). 


\section{lavozdelsur.es}

Nadie quiere recoger fresas en Huelva: 23.000 empleos ofertados y sólo 970 solicitudes

19.000 temporeras marroquíes cubrirán la campaña dado el bajo índice de solicitudes en España

LAVOZDELSUR.ES $\boldsymbol{\Downarrow} 18$ DE FEBRERO, 2019 ๓ MENOS DE UN MINUTO

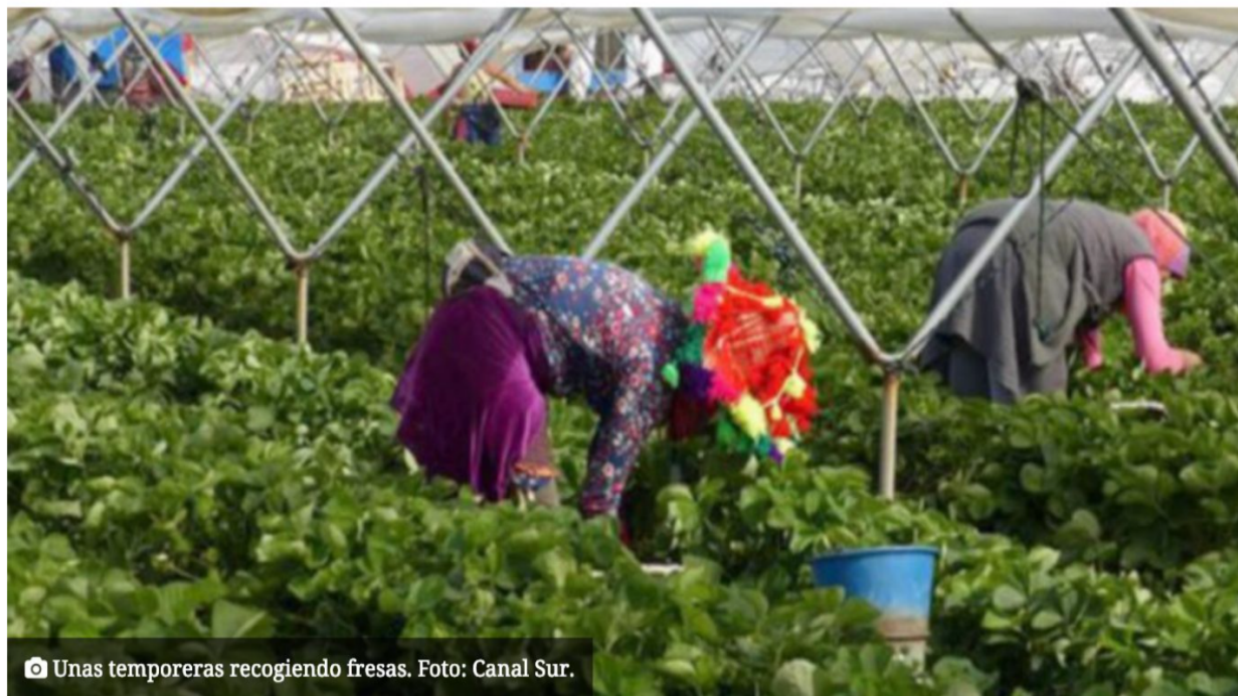

En Huelva, la tercera provincia con la tasa más alta de desempleo de España (22,79\%), sólo un 4,2\% de las solicitudes de empleo para trabajar en la campaña de la fresa se han completado: $\mathbf{9 7 0}$ de $\mathbf{2 3 . 0 0 0}$ empleos que ha puesto a disposición el Servicio Andaluz de Empleo (SAE).

La oferta del SAE este año ha duplicado a la del año pasado, cuando fueron 11.000, pero de la misma que forma que en 2018 las personas interesadas ni siquiera han llegado al millar. Es por ello que las asociaciones y organizaciones agrarias, bajo la coordinación de técnicos de Asaja, COAG, UPA y Freshuelva, vuelven a desplazarse a Marruecos para seleccionar 7.500 temporeras, que se sumará a las 11.500 que repiten del año pasado.

El Ministerio de Trabajo, Migraciones y Seguridad Social, de hecho, ha autorizado la contratación de $\mathbf{1 9 . 1 7 9}$ trabajadoras marroquíes, que serán las encargadas de cubrir la campaña de la fresa en Huelva ante la falta de solicitudes en España.

Figura 1. Noticia de la actividad 
La intención es sencilla: a través del análisis de la realidad (la noticia de prensa, recogida en la imagen adjunta) nuestras alumnas y alumnos van a empezar a cuestionar uno de los mantras más queridos del pensamiento ultraconservador, a saber: que los inmigrantes "roban" los puestos de trabajo a los trabajadores del país. Pero sobre el documento, el docente no ofrece respuestas; sólo una pregunta: “¿Por qué crees tú que prácticamente ninguna persona quiere trabajar en la cosecha de la fresa en Huelva?".

Son las alumnas y alumnos los que han de proponer sus hipótesis. El docente se ha de limitar a ordenar la recogida y puesta en común de las mismas. A continuación, propone escuchar el testimonio de las personas trabajadoras que viven en ese lugar. ${ }^{5}$ Tras ello, se propone una segunda actividad: "Después de escuchar, ¿qué preguntas te vienen a la cabeza?".

Y tras la puesta en común de esas cuestiones, se propone como tarea final la redacción de un pequeño ensayo: "Con lo que sabes, explica qué es lo que está sucediendo en el sector de la fresa en Huelva".

En todo el proceso, todos los alumnos y alumnas participan; todos y todas aportan. Y todos y todas son capaces de, a su modo, ordenar sus ideas y expresar sus propias conclusiones, tras haber escuchado, razonado y hablado con sus compañeros y compañeras y, cómo no, con el docente.

Obviamente, dirigir una sesión de trabajo de estas características con 25 o 30 adolescentes no es una tarea fácil. Requiere por parte del docente sensibilidad, oficio y destreza en el manejo del aula. Requiere en definitiva una buena formación docente. Pero el resultado es, primero, un aprendizaje de calidad y segundo, un grupo de trabajo (clase) en el que ningún alumno/a es descartado. Todos participan, todos aprenden y en cierto modo, todos enseñan a los demás. ${ }^{6}$ Como efecto colateral, la motivación del conjunto del alumnado se dispara y en consecuencia la necesidad de "controlar" la clase (en el sentido disciplinario del término) desaparece casi por completo (Vaello, 2006, p. 97).

Lógicamente, si como docentes no nos interesa el cuestionamiento de la realidad, si por ejemplo la explotación laboral nos parece un mal necesario de nuestros tiempos, si creemos que en todo caso no se puede hacer nada para remediarlo y que lo único que queda es resignarse, si ideológica y humanamente estamos ahí, nuestro paradigma metodológico es el de la educación bancaria, y no desde luego el de la pedagogía crítica y Gea-Clío. Gea-Clío apunta como objetivo final de la enseñanza obligatoria a la construcción de una ciudadanía comprometida, co-responsable y consciente de la realidad que le rodea. Sólo la comprensión de la realidad permite la acción sobre esa realidad. Si el entorno no es inteligible, es imposible actuar de forma consciente y responsable sobre él. Por ello la historia y la geografía enseñadas en las aulas han de serlo dentro de un paradigma esencialmente crítico. Así, "tanto en los problemas que afectan a las consecuencias ambientales de la acción antrópica, como al deseo de cambiar de domicilio, de visitar un lugar de vacaciones, organizar el espacio de un patio escolar [...] En todas estas escalas es posible intervenir [...] Y así desde el pensar local se construye un actuar global" (Souto, 2019, p. 27). Es en estas coordenadas en las que Gea-Clío sitúa y entiende la enseñanza de la Geografía y la Historia. Y es en este marco, en “socializar en la reflexión y en la argumentación” (Souto, 1999, p. 57), en el que se sitúan sus principios metodológicos.

\footnotetext{
${ }^{5} \mathrm{El}$ material audiovisual utilizado son entrevistas cortas de un programa de televisión en el que trabajadores del lugar responden a preguntas sobre cuál es el salario, las condiciones de trabajo reales, etc. Puede verse aquí: (https://geollenguablog.wordpress.com/2019/02/28/ens-furten-el-treball_).

${ }^{6}$ Otro ejemplo ilustrativo del trabajo de Gea-Clío, en este caso a caballo entre educación primaria y secundaria, lo constituye el proyecto "Pou Clar" llevado a cabo en la localidad valenciana de Ontinyent (Martínez y Campo, 2017).
} 
Los planteamientos del grupo Gea-Clío no se han quedado desde luego en la mera teoría. La producción del grupo desde su fundación en 1989 se ha caracterizado por su naturaleza fundamentalmente práctica. Así, la edición por parte del grupo de materiales de aula ha sido ingente: libros de texto, cuadernos de trabajo, guías para el profesorado, etc. ${ }^{7}$ Como comunidad de práctica, las diferentes líneas de investigación del grupo (Souto, 2011b, p. 16 y ss.) han estado siempre en relación y contacto permanente con la experimentación y el trabajo en el aula.

\section{Conclusiones}

Así, frente a la conceptualización de la diversidad en las aulas como problema, la tesis de Gea-Clío es que el problema de la diversidad como tal no existe: la diversidad no es un problema, la diversidad es una manifestación más de la normalidad, entendida esta como realidad efectivamente existente (y no idealizada). El verdadero problema es abordar la diversidad con metodologías bancarias, selectivas y excluyentes que en el caso de la Geografía y la Historia lo único que ofrecen al alumnado es la mera absorción pasiva de ingentes cantidades de contenidos descriptivos, absorción que luego es medida mediante los consabidos exámenes. Si en lugar de la absorción-reproducción planteamos en su lugar el paradigma metodológico de la reflexión-creación, los resultados varían diametralmente, incluso en entornos educativos complejos (Giménez Urraco, 2014). Así, los resultados cualitativos obtenidos en aulas de especial complejidad corroboran esta tesis (Souto et al., 2018). Cuando en este tipo de aulas el proceso de enseñanza-aprendizaje se aborda desde la perspectiva crítica-dialéctica antes descrita, los progresos del alumnado son acelerados y muy notables. Obviamente, este planteamiento metodológico ha de ir acompañado también de otro tipo de medidas paralelas. Pero todo ello conduce a lo que comúnmente se conoce como éxito educativo. Chicos y chicas en teoría pertenecientes a esa "diversidad" potencialmente problemática según la escuela bancaria, cuando trabajan dentro de los parámetros pedagógicos arriba señalados, obtienen resultados de todo punto satisfactorios y continúan con éxito su educación más allá de la etapa obligatoria.

Como señalábamos líneas arriba, Gea-Clío no es un proyecto aislado; forma parte de una corriente pedagógica alternativa que a nivel estatal está ofreciendo desde hace años alternativas "de éxito”. Por ejemplo en el marco del proyecto IRES (Investigación y Renovación Escolar) se están llevando a cabo experiencias que abordan el "problema" de la convivencia desde un punto de partida completamente en las antípodas del modelo institucional, abordando la cuestión dentro del aula desde el análisis del conflicto en sí, utilizándolo como objeto de estudio (como contenido curricular) alrededor del cual generar al mismo tiempo crecimiento intelectual/académico y reflexión social. En definitiva una propuesta real, pedagógicamente fundamentada, puesta en práctica a pie de aula, y que impugna abiertamente los principios (puramente punitivos) del modelo institucional actualmente imperante (Pineda Alfonso y García Pérez, 2017.)

El gran reto del futuro es cómo lograr que metodologías y propuestas de éxito como las planteadas por Gea-Clío, IRES y otros colectivos en el terreno de la enseñanza-aprendizaje de las ciencias sociales, logren extenderse de forma generalizada. Después de 30 años de actividad (en el caso de Gea-Clío) es evidente que el efecto "contagio", con ser potente, tiene sin embargo sus limitaciones. Quizás ya va siendo hora de que desde el ámbito de la política española, treinta años después de la instauración de la Educación Secundaria Obligatoria, se tome seriamente cartas en el asunto y se lleve a cabo una nueva reforma en profundidad en tres direcciones: una, en la mejora sistémica de la formación pedagógica de los docentes de la etapa obligatoria 12-16. Otra, en la

\footnotetext{
${ }^{7}$ Parte de todo ello puede verse aquí: $\underline{\text { http://socialsuv.org/gea-clio/ }}$
} 
manera en que son seleccionados los y las profesionales que de forma definitiva trabajan impartiendo enseñanza en la red pública (Martínez Bonafé y Souto, 2019), implementando un nuevo sistema que busque en los candidatos y candidatas no sólo la excelencia académica, sino también una formación pedagógica y metodológica igualmente sólida. Y una tercera, en la eliminación de la capacidad de facto de los centros privados-concertados de escoger a la carta a su alumnado, un fenómeno masivo de segregación escolar que daña la calidad del conjunto del sistema educativo. En todo caso, la respuesta a cómo podemos mejorar nuestro sistema educativo no está desde luego en culpabilizar, etiquetar y segregar a (una parte significativa de) los alumnos y alumnas que "obligatoriamente" sentamos en las aulas.

\section{Referencias}

Duarte, O. (2018). La Enseñanza de la Historia: innovación y continuidad desde Rafael Altamira. Revista Española de Pedagogía, 76(269), 141-155. doi: 10.22550/REP76-1-2018-07

Fernández Enguita, M., Mena, L. y Riviere, J. (2010) Fracaso y abandono escolar en España. Barcelona: Fundación la Caixa.

Freire, P. (1970/2005). Pedagogía del oprimido. México: Siglo XXI.

Generalitat Valenciana (2010). Ley 15/2010, de 3 de diciembre, de la Generalitat, de Autoridad del Profesorado. Diari Oficial de la Generalitat Valenciana (6414) pp. 44887-44890. Valencia: Generalitat Valenciana.

Giménez Urraco, E. (2014). Práctica pedagógica en un centro de atención educativa singular de un barrio de acción preferente. Aproximación desde la teoría de Basil Bernstein. (Tesis doctoral). Universitat de València, Valencia

Grup Germania-75 (1980). Materiales para la clase de Historia I. Proyecto experimental de didáctica de la Historia para un primer curso de B.U.P. Madrid: Anaya.

INEE-Instituto Nacional de Evaluación Educativa (2018). Sistema estatal de indicadores de la educación 2018. Madrid: Ministerio de Educación y Formación Profesional.

La Voz del Sur (2019). Nadie quiere recoger fresas en Huelva: 23.000 empleos ofertados y sólo 970 solicitudes. (2019, 18 febrero). lavozdelsur.es. Disponible en: https://www.lavozdelsur.es/nadiequiere-recoger-fresas-en-huelva-23-000-empleos-ofertados-y-solo-970-solicitudes/

Martínez Bonafé, A. y Souto, X.M. (2019, mayo). Las oposiciones para profesorado de secundaria. Un debate necesario. Aula de Secundaria, 31, 32-36.

Martínez, J.S. (2017). La equidady la educación. Madrid: Catarata.

Martínez, M. y Campo, B. (2017) Saber geografía mediante un problema escolar: ¿Nos seguiremos bañando en el Pou Clar? En García, D., Martínez, S. y Souto, X.M. (Eds.), Las buenas praxis escolares: investigar desde la práctica del aula (PP. 141-152). Valencia: Nau Llibres.

MEC-Ministerio de Educación y Ciencia (2006). Las cifras de la educación en España. Madrid: MEC.

MEFP-Ministerio de Educación y Formación Profesional (2018). Datos y cifras. Curso escolar 2018/2019. Madrid: MEFP.

Moreno, J. y García, R. (2008). El profesorado y la secundaria: ¿demasiados retos? Valencia: Nau Llibres.

Pérez, P., Ramírez, S., Souto, X.M. (1997). ¿Cómo abordar los problemas ambientales y sociales desde el aula? Valencia: Nau Llibres.

Pineda Alfonso, J. A. y García Pérez, F. F. (2014, diciembre). Convivencia y disciplina en el espacio escolar: discursos y realidades. Scripta Nova, 18(496),1-21. Disponible en: http://www.ub.edu/geocrit//sn/sn-496/496-05.pdf

Pineda Alfonso, J. A. y García Pérez, F. F. (2016) Conflicto y convivencia. Profesores y alumnos en el proceso de enseñanza en un aula de secundaria. Revista Mexicana de Investigación Educativa, 
71(21), 1073-1091. Disponible en:

http://www.comie.org.mx/v1/revista/portal.php?idm=es\&sec $=\mathrm{SC} 03 \& \&$ sub $=\mathrm{SBB} \& \mathrm{criterio}=$ ART71003

Pineda Alfonso, J. A. y García Pérez, F. F. (2017). La enseñanza del conflicto y la convivencia en la educación secundaria. Magis, Revista Internacional De Investigación En Educación, 10(20), 143-158. doi: https://doi.org/10.11144/Javeriana.m10-20.cfse

Ruiz, F., y Martínez, M. (2017). L’organització de l’àmbit sociolingüístic en 1r i 2n ESO. En García, D., Martínez, S. y Souto, X.M. (Eds.), Las buenas praxis escolares: investigar desde la práctica del aula (pp. 101-114). Valencia: Nau Llibres.

Souto, X.M. (1999). Los proyectos de innovación didáctica: El caso del proyecto Gea-Clío y la didáctica de la Geografía e Historia. Didáctica de las Ciencias Experimentales y sociales, 13, 55-79.

Souto, X.M. (2011a). La innovación educativa a través de los grupos de trabajo. En Moreno, J. y Barranco, E. Innovación y práctica educativa: experiencias con buenos resultados (pp. 147-162). Valencia: Nau llibres.

Souto, X.M. (2011b). La construcción del conocimiento escolar en la sociedad de las comunicaciones. Una propuesta del Proyecto Gea-Clío. Investigación en la escuela, 75, 7-19.

Souto, X.M. (2019). La representación escolar de la geografía. En Valero, J. y Fuertes, A. (Eds), I Congrés d'Humanitats, Ciències Socials i Educació. Alacant, 1 i 2 de juny de 2018 (pp. 13-28). Alacant: Universitat d'Alacant.

Souto, X.M., Campo, B., Císcar, J. y Mira, A. (2018). La construcción del espacio escolar y las marginaciones personales. Revista Científica Faculdade de Balsas, 9(1) 89-113.

Tarabini, A. (2018). La escuela no es para ti. El rol de los centros educativos en el abandono escolar. Barcelona: Octaedro.

Vaello, J. (2006). El clima de clase: Problemas y soluciones. En Moreno, A. (Dir.) y Soler, M. P. (Doord.). La disrupción en las aulas. Problemas y soluciones (pp. 83-99). Madrid: Ministerio de Educación y Ciencia.

\section{Información sobre el autor}

Autor: Arnaldo Mira Pérez

Institución: Universitat de València

Email: arnaldo.mira@uv.es 


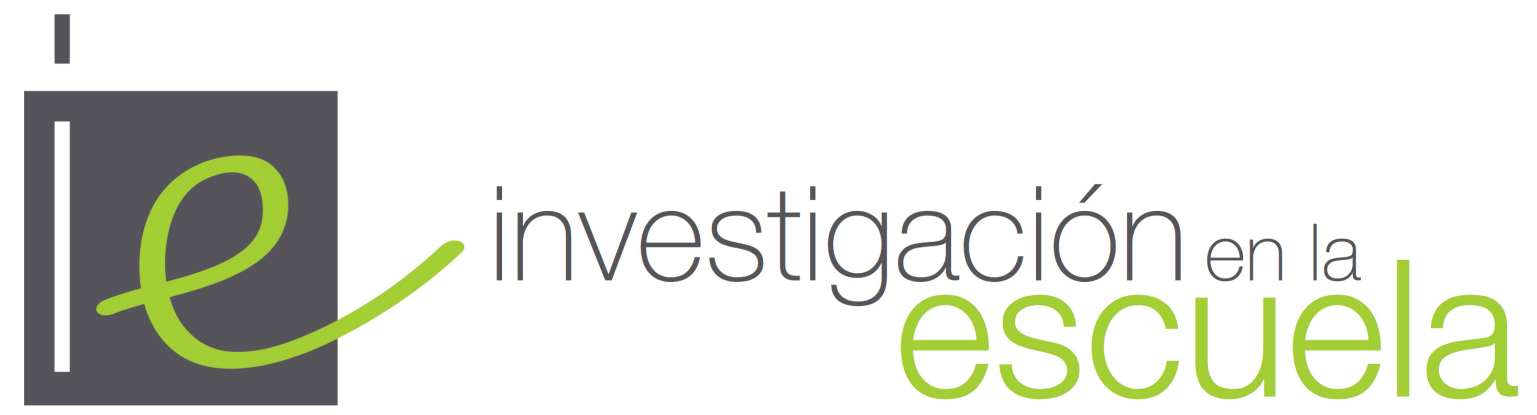

Revista académica evaluada por pares y de acceso abierto

Número 98

31 de julio de 2019

ISSN 2443-9991

\section{(c) (i) (2)}

Esta obra está bajo una licencia Creative Commons. Los/as lectores/as pueden compartir, copiar y redistribuir el material en cualquier medio o formato, así como adaptar, remezclar, transformar y construir a partir del material para cualquier propósito, incluso comercialmente. Para ello, deben de hacerlo bajo los siguientes términos: dando crédito de forma adecuada, brindando un enlace a la licencia e indicando si se han realizado cambios. Si se remezcla, transforma o crea a partir del material, debe distribuir su contribución bajo la misma licencia del original.

Más detalles de la licencia de CreativeCommons se encuentran en https://creativecommons.org/licenses/by-sa/4.0/deed.es

Cualquier otro uso debe ser aprobado en conjunto por el autor/es, o Investigación en la Escuela.

Uิ

Revista Editada por la Universidad de Sevilla. https://editorial.us.es/es/revistainvestigacion-en-la-escuela

Por errores y sugerencias contacte a secretaria@investigacionenlaescuela.es

La revista Investigación en la Escuela desde su origen en 1987 hasta su no 87 (2015) fue editada por Díada Editora. 
